\title{
LESSONS FROM THE EVALUATION OF A PUBLIC OUT-PATIENT SUBSTANCE ABUSE TREATMENT PROGRAMME IN THE WESTERN CAPE
}

\section{Anna Strebel, Tamara Shefer, Maria Stacey, Nokuthula Shabalala}

\section{INTRODUCTION}

Substance abuse is widely regarded as a major health and social problem in South Africa, and particularly in the Western Cape (Corrigall, Ward, Stinson, Struthers, Frantz, Lund, Flisher \& Joska, 2007; Myers, Fakier \& Louw, 2009). The complex nature of patterns of substance abuse, as well as the particular problems associated with this abuse, has implications for the development and implementation of treatment interventions. The most common primary drug of abuse in the Western Cape amongst patients admitted to treatment programmes is methamphetamine (known locally as "tik") (Dada, Plüddemann, Parry, Vawda \& Fourie, 2012). The previous decade saw a dramatic rise in methamphetamine (hereafter indicated as MA) use, particularly among youths, with over half the patients in treatment for MA abuse being younger than 25 years (Plüddemann, Parry, Dada, Bhana, Bachoo \& Fourie, 2010). MA is also often used in combination with other drugs, and this prevalence of poly-substance abuse needs to be taken into account in the planning of services (Harker, Kader, Myers, Falkier, Parry, Flisher, Peltzer, Ramlagan \& Davids, 2008).

Another public health concern related to substance abuse locally is the increased risk of contracting sexually transmitted infections, particularly HIV, as a result of the disinhibition associated with MA use (Parry, Blank \& Pithey, 2007; Staras, Tobler, Malonado-Molina \& Cook, 2011; Wechsberg, Jones, Zule, Myers, Browne, Kaufman, Luseno, Flisher \& Parry, 2010). MA is also linked to aggressive behaviour and is implicated in a high proportion of both crimes and trauma cases reported in the Western Cape (Parry, Plüddemann, Louw \& Leggett, 2004; Plüddemann, Parry, Donson \& Sukhai, 2004). Thus there is clearly an urgent social need for the development of effective MA treatment policy and programmes (Harker et al., 2008).

There is also considerable evidence pointing to the co-occurrence of other mental health problems together with substance abuse. In the USA, for example, a study found that adults who used illicit drugs were more than twice as likely to have serious psychological distress (SPD) than those who did not use drugs, while illicit drug use was more than twice as common amongst adults with SPD compared to those without SPD (SAMHSA, 2005). Likewise in South Africa, there is evidence of the co-occurrence of substance abuse and other mental illnesses, which has increased the burden placed on already inadequate inpatient and out-patient mental health services, for example, in the Western Cape (Myers, 2006; Plüddemann, Myers \& Parry, 2008; Weich \& Pienaar, 2009). This also then has implications for how treatment programmes are conceptualised.

At the level of treatment, while South Africa aims towards implementing an integrated national response to substance abuse (Department of Social Development, 2007), in 
practice substance abuse treatment services are beset by multiple challenges, including lack of planning and coordination, inadequate services to meet the demand, inadequate resources, and a lack of evidence-based practices (Myers, Louw \& Fakier, 2008a; Parry, 2005). Furthermore, although the management of co-occurring mental disorders improves client retention and treatment outcomes (Centre for Substance Abuse Treatment, 2005), few treatment facilities provide this service, and those that do provide this service are more likely to be in-patient as opposed to out-patient, and more likely to be private than state-funded or not-for-profit (Myers \& Fakier, 2009).

The programme evaluated in this study is a collaborative partnership between the Provincial Departments of Social Development and of Health, and a national public sector substance abuse treatment centre branch in the Western Cape province. It was developed to provide a comprehensive and structured multidisciplinary out-patient service to local communities in high-risk substance abuse areas in the Western Cape.

The programme hinges around a "one-stop shop" for all aspects of substance abuse, involving screening, comprehensive assessment (including the capacity to make dual diagnoses), and participation in a well-known evidence-based four-month psychoeducational programme (Rawson \& McCann, 2002). Together with group-based sessions, clients are offered individual counselling, family and occupational therapy sessions, consultation with the clinical psychologist, psychiatric nurse and consulting psychiatrist, as well as aftercare sessions for those who have completed the programme. An annual external process evaluation of the impact and effectiveness of the programme was introduced. This study reports on external evaluations of the programme during 2008 and 2009 in order to identify issues for consideration in enhancing such public out-patient substance abuse programmes.

\section{METHODS}

Similar methods were employed for both evaluations in order to allow for comparisons across the two years. Data gathering involved qualitative and quantitative methods, and included a number of phases. Firstly, preliminary and follow-up consultations with agency staff were held to clarify expectations, establish procedures, operationalise key indicators and to develop appropriate evaluation tools. Secondly, available computerised client records and statistical data for 2008 and 2009 were investigated for possible quantitative evidence of impact. Thirdly, fieldwork evaluations of client, family and staff experiences and perceptions of the impact of the programme were conducted, as outlined below.

In 2008 in-depth individual interviews were conducted with six key managers of the programme, which included members of the programme task team. These were a senior representative from each of the two government departments involved, the provincial director of the organisation, the manager of the programme and two consultant psychiatrists. In addition, a focus group discussion was conducted with five staff working in the programme, namely three social workers, who were responsible for running most of the group sessions, one psychiatric nurse and one occupational therapist. Next, individual semi-structured interviews or focus group discussions were 
conducted with clients. These explored what clients' experiences of the programme as well as the staff had been, what they considered to be its strengths, and what could be done to improve the programme. Nine individual interviews were conducted with clients of the programme, some who had completed the programme, and some who had dropped out before completion; two focus group discussions with current clients of the programme were also held. In addition, one focus group discussion was held with family members of those in the treatment programme.

In 2009 in-depth individual interviews were conducted with five managers of the programme, including members of the programme task team, which again involved senior representatives from the two government departments involved, the provincial director of the organisation, the manager of the programme and one consultant psychiatrist. In addition, a focus group discussion was conducted with the five staff working in the programme, namely three social workers, one psychiatric nurse and one occupational therapist. In respect of the clients, three focus groups were conducted, two with those currently in the programme, and one with those in the aftercare programme; in addition, five individual interviews were held with clients who had left before completion of the programme.

The interviews and focus group discussions were conducted by members of the external research team in an appropriate language for participants (English, Afrikaans or Xhosa, the official languages of the province). The interviews were audio-taped with the permission of participants, transcribed verbatim and translated where necessary.

All standard ethical procedures for research with human subjects were adhered to, including signed informed consent, assurance of confidentiality and anonymity of the interviewees, and the option to leave the research at any time, if they so wished. Regarding data analysis, only descriptive statistics were generated, given the nature of the available computerised client data, while qualitative thematic analysis (Braun \& Clarke, 2006) was conducted on the interview transcripts.

\section{RESULTS}

Regarding quantitative data, for a number of reasons client data were not captured by programme staff in a similar way over the two-year period, so that direct comparisons were very difficult. Thus only demographic data on gender and age are reported here. Most clients were male (72\% in 2008 and 65\% in 2009). Regarding age, in $200833 \%$ were aged $22-30,42 \%$ were 21 and younger, and $25 \%$ were older than 30 years of age; in 2009 the figures were 56\% aged 22-30, 21\% aged 21 years and younger, and 22\% over 30 years. Thus findings for the two periods indicate that the programme serviced mainly coloured ${ }^{1}$ males in the young adult age group (aged 18-29), which reflects documented patterns of substance abuse for the Western Cape (Van Heerden, Grimsrud, Seedat, Myer, Williams \& Stein, 2009). In addition, it appears that the trends in group

\footnotetext{
${ }^{1}$ Racial categories were not recorded by the treatment agency, but some conclusions can be drawn from the language of participants, and staff confirmed this profile.
} 
attendance over both periods for which data were available increased somewhat, while testing of urine demonstrated an increase in negative results. ${ }^{2}$

\section{Qualitative findings}

Although staff/management and client interviews focused on somewhat different aspects of the programme, with the main difference being additional questions to staff about the specific model of intervention, there was considerable overlap in the issues raised, and so findings are reported in an integrated way when appropriate. ${ }^{3}$ In addition, findings for the two evaluations are largely combined, but any shifts in perceptions over the period are highlighted. First we focus on identified strengths of the programme, as reported by participants; we then elaborate on aspects of the programme which were regarded by key stakeholders as being less successful; and finally we present suggestions for improvement and strengthening of such out-patient public sector substance abuse treatment programmes.

\section{Participant experiences of the strengths of the out-patient substance abuse programme}

Both staff and client participants viewed the substance abuse programme in a very positive light. For clients, experiences of the programme were mostly consistent across the two years. Overall, they felt that the programme met their needs in addressing their substance-related problems, as well as focusing on improving their insight and relapseprevention skills. They valued the structured group and participatory nature of the programme, highlighting the attainment of knowledge, understanding and skills, as captured in the quotations below:

"I got skills on how to prevent relapse, how to deal with emotional issues that make me want to use again." (Client, 2008)

"We also learned the map of recovery, withdrawal, honeymoon ... how the chemicals in the brain are overdosing, you feel stronger, energetic, get up early." (Client, 2009)

"To learn how to socialise again with people, getting back to how you were before you were using drugs. ” (Client, 2008)

Working in a group with others with whom they could identify and who shared their experiences was particularly valued:

"We could be open about what we went through; the people there had the same problems as us." (Client, 2009)

They also appreciated the family component of the programme (which included family counselling sessions, and weekly family support group sessions for clients and their families), which is a central aspect of the intervention, ensuring that the family gains

\footnotetext{
${ }^{2}$ Figures are not provided here, as the periods and methods of measurement were not consistent across the two years.

${ }^{3}$ Quotations from participants are identified as either from programme staff/management, or clients, as well as the year of evaluation.
} 
valuable understanding of what the client needs as he or she withdraws from drugs and engages in the programme:

"The Saturday family group is a good idea as the family now also learn what we are going through and we have something to speak about." (Client, 2008)

"They [referring to the staff] provide me with the tools to identify and understand their problems and to help them help themselves." (Parent, 2008)

Client participants also commented very positively on the attitudes and competence of the staff, whom they found encouraging and promoting of their continued attendance and success on the programme:

"The way they [referring to the staff] communicate ... they are professional; they know how to handle you. They understand you, can read you. I have never experienced such a thing before." (Client, 2009)

"They made a very caring, supportive environment." (Client, 2008)

"Their dedication is so encouraging, makes me want to come back. They don't judge people. They are never grumpy or in a down mood. They are not here just because of being paid, they really want to help." (Client, 2009)

Client participants rated the programme very favourably in comparison to other types of intervention they had experienced, and felt that they would definitely return to the programme if they needed help again. A key strength of the programme for many participants related to its out-patient nature, with participants suggesting that in-patient programmes did not adequately address the realities they faced once they returned to their home context:

"It's one of the best programmes you can get in South Africa now." (Client, 2009)

"I know of people who had gone to other places and this one was totally different. It was the best one they had encountered." (Client, 2008)

"The other things [referring to other in-patient programmes] don't prepare you for the outside world. It is not in the real world where it happens." (Client, 2008)

For programme staff and management there were two main strengths of the programme. Firstly, the one-stop multidisciplinary approach was viewed as a major strength, as was the fact that a diagnosis of psychiatric co-morbidity was possible. At follow-up, these strengths were seen to have been consolidated:

"When we look at the kind of scenario of substance abuse in the country, and especially the Western Cape, this is the answer for treating clients effectively ... often we have people with dual diagnosis problems, people living with HIV, a vast range of other overlapping problems." (Staff, 2008)

"The multidisciplinary team is good ... My sense is that it's been going very well, they've become the benchmark of the multidisciplinary approach for other 
programmes. And that is quite rewarding in terms of the effort that we've put in, us [referring to the provincial department] and them." (Staff, 2009)

Also, staff participants valued the model of intervention, with its participatory, collaborative, non-judgemental, evidence-based and manualised format, which was experienced by the social workers and other staff involved in presenting it as accessible and easy to implement:

"The [name of programme] is well researched. It has homework, hand-outs and some videos that go along with it. It is a well-developed, integrated, standardised programme with a good facilitator's manual." (Staff, 2008)

"The approach is very positive, non-punitive and motivational ... [the] staff enjoys implementing it." (Staff, 2008)

Moreover, management and staff highlighted the visible success of the programme with especially tik users. Following a concern raised in 2008 by both staff and clients regarding the absence of a specific focus on heroin abuse, which staff claimed was on the increase as a drug of choice in this region of South Africa, a dedicated poly-substance programme has also been introduced and participants were satisfied that this was beginning to meet the needs of the poly-substance users as well:

"There are more people completing, which is encouraging. More than our estimated targets for completion have been met ... we have been amazed by the successes with tik addicts in particular, in the first month they start coming clean." (Staff, 2008)

"Heroin is much more tricky, we need to think about devising a longer psychosocial programme with medication as well, right now we are failing our clients, as they are graduating from the programme but are still using heroin." (Staff, 2008)

"We've started the poly-substance group ... lots of heroin addicts come to [name of programme] but [it] doesn't work that well with them ... [Name of programme] is meant for stimulant use, so it's very successful with tik, but not so well with heroin." (Staff, 2009)

In addition, the staff were positive about the emphasis placed on the aftercare services for those who had completed the programme towards ensuring that they maintain their drugabstention status:

"An important innovation is the aftercare component, clients continue after the four-month programme to attend supportive, structured aftercare." (Staff, 2008)

Secondly, staff and management considered the partnership between the Departments of Health and of Social Development to be very successful and a core strength of the programme. This was seen as a relatively novel collaboration in the area of substance abuse outside of the medical context and in-patient programmes. Replication of the treatment model was also seen to be desirable and had apparently started to occur: 
"The partnership is fabulous, we have a good relationship. We are on the same wavelength. We are each clear on our roles. We understand that we need each other." (Staff, 2008)

"I think, being in the government for quite a number of years, departments working together has always been a major challenge, and I really think that the partnership has developed quite strongly." (Staff, 2009)

"I'm very excited about the partnership, and I' $m$ very excited about the partnership between the two departments, but also bringing the NGOs factor into the whole thing. " (Staff, 2009)

"Replication is already in progress, especially through the hospital connection. Personally I see it as an effective model and would like to see similar programmes throughout the province, so we are hoping to replicate the multi-disciplinary team and [name of programme] at all our offices." (Staff, 2009)

\section{Participant perceptions of challenges to the effectiveness of the programme}

There was also considerable overlap between the experiences of clients and staff/management of the programme regarding the challenges it faced. While some concerns identified in the first evaluation had been addressed, others had been more difficult to tackle successfully.

Regarding the model of intervention, while the out-patient nature of the programme was viewed as a strength, there were also challenges in this respect related to substance abusers' exposure to multiple triggers. Clients and staff in both evaluations pointed to the need for the programme activities to be expanded, and more resources and incentives to be made available to assist with job skills, career development and re-integration into their home communities:

"I hate coming home - there are a lot of triggers at home. I feel free here, but at home it's not easy. Friday, Saturday and Sunday are really hard; I want to do some more leisure on weekends - anything can trigger us. So I will be happy for anything to keep me busy." (Client, 2009)

"We are intending an extension of the programme ... more activities and stuff are needed ... linking with resources in the community. "' (Staff, 2008)

"And then to really look again at the motivational behavioural approach, we need more rewards and acknowledgements, and more continuous networking with resources ... Ideally you would like Department of Labour to come in as well, to get people to move from there to a skills development situation." (Staff, 2009)

Moreover, other programme improvements were needed, including the translation of client hand-outs into the other two languages of the province and further adaption to local contexts:

"Services need to be culturally appropriate, contextual, counselling is relational, so it must be contextual." (Staff, 2008) 
"They need to make the language of the model more understandable - you must remember most of our clients are not the educated, so you need to make the language simple, especially with the DVDs." (Staff, 2009)

"We are Africanising everything, the [name of the programme] is very American but we pitch it in an African way, all our delivery is pitched at where we are, we use our own images." (Staff, 2009)

In addition, the aftercare and family components of the programme needed more attention:

"The aftercare programme is a challenging service to render, we need to get people in and through aftercare ... We have very specific outputs from aftercare and don't see it - perhaps we need to shift the goal post or improve." (Staff, 2009)

"We must never underestimate the role of the family. There is a huge need to get them to be part of the programme, to get them to understand the problem and how to handle it in the family ... less than $40 \%$ are coming to family sessions. At the moment when family members are also involved, there is probably a more effective outcome. Family is part of the treatment plan." (Staff, 2008)

"Our family stuff is cool, some good stuff, but there is not nearly enough, it's not as formal as it could be, there's a lack, a lot of policy, procedural and programme stuff." (Staff, 2009)

Staff considered that by 2009 a greater focus on increasing individual sessions with clients had been achieved, especially in the first month of the programme, which they felt could help with improving client retention:

"In the first month there is no particular mechanism [for more individual attention] put in place." (Staff, 2008)

"Staff are more equipped now to do individual and assessment work. We have taken up the problem of not enough individual sessions and we have addressed this." (Staff, 2009)

Regarding staffing of the programme, in the initial evaluation it was felt there was still some resistance among staff to the integrated model of treatment, although this was thought to have improved significantly by the second evaluation. Moreover, team staff seemed to experience greater job satisfaction, and were thought to be better trained, more professional and competent, as well as confident in implementing the structured programme as at the previous evaluation:

"Staff turnover is a good indicator, we have retained most staff over last year; there has been only 10\% turnover across the board, which is very positive." (Staff, 2009)

"I was amazed at the amount of growth in the team ... I was pleasantly surprised at how the team had developed ... there's always room for improvement, one shouldn't be complacent, but I get a feeling that staff seem much more confident in their understanding of patients and their understanding of addictions, in working out treatment plans for patients, picking up problems." (Staff, 2009) 
Also, initial concerns about lack of consultation of management with implementing staff, and the need for more attention to be paid to issues of organisational climate, had to some extent been addressed by the second evaluation. Participants highlighted the importance of regular consultation, training and support for staff involved in such a programme, especially regarding working in a multidisciplinary team:

"In the past it seemed to feel like there was so much toxic stuff happening amongst them, there was a whole posturing for position and power going on, and I feel there was a whole tension for the social workers around the new team coming in, the psychologist ... but it feels like it's dissipated in the last while." (Staff, 2009)

"Things started a while ago, a lot has changed I think, staff attitudes have changed, I think staff knowledge has changed, I think staff skills have changed [pause] and I think the multidisciplinary team has enriched." (Staff, 2009)

"What we have learned for replication is that a lot of training needs to be done at such new sites; we need to help people look at minimum norms and standards; the appointment and training of staff; a close supervision/management of new sites to help the service get underway." (Staff, 2009)

"The multidisciplinary team works well. For me that's one of our strengths, for the out-patient programme to have a multi-disciplinary team is an added bonus. It's common in in-patient programmes but not in out-patients. All the disciplines support each other." (Staff, 2009)

A major concern for all participants that had not shown notable improvement over the period of evaluations was the high "drop-out" rate of clients during the programme, especially during the initial phase of the programme, and the difficulty of improving retention of clients in the various phases of the programme:

"We lose them [referring to the clients] especially in the first couple of weeks of attending the open group when we haven't yet established relationships." (Staff, 2008)

"My concern about the programme, and that I've seen from being involved in our districts has always been the drop-out rate, and that they've had quite a huge dropout rate, I think at one stage they reported back it was up to 60\%." (Staff, 2009)

"In my opinion, how we can retain clients, that's the biggest challenge because on Mondays we get high numbers, say on the stats you see 20 booked but only 5 turn up. So say we see 20 and we place them in different groups. On Friday when we do a check to see what's happened then you find maybe only 4 turned up." (Staff, 2009)

The other core concern, which was raised in both evaluations, was the continued absence of a comprehensive, streamlined and user-friendly system of data capturing, as well as the need to develop clear indicators of success, and to establish policies, procedures and tools for continuous monitoring and evaluation of the programme. This seemed to be the component of the programme in which least progress had been made, as also found in an 
earlier evaluation of the programme (Kansky, 2008), and highlighted by the dearth of quantitative data available for the two evaluations reported in this study:

"Especially problematic is the $M \& E$ system, the database system is inaccessible and difficult to understand, and there are multiple forms of record keeping that do not speak to each other ... I'm not sure if our system of $M \& E$ is working well enough." (Staff, 2008)

"I haven't seen statistics, I asked for some recently, but couldn't make any sense of them, maybe it was just in a format I couldn't understand, but I couldn't make much sense of them, I would've liked to have thought that this was an area that would have been improved ... it is so critical ... but the filing and information management is something that they should be taking responsibility for." (Staff, 2009)

"There is a challenge to still evaluate the outcomes of the programme, I'm not sure if the form is adequate enough, the indicators are very broad and we have not taken it further than the previous one, so there an urgent challenge is to look at the monitoring and evaluation system." (Staff, 2009)

In conclusion, then, there were a number of issues that emerged clearly from the two evaluations. Firstly, there was a considerable amount of positive sentiment about the programme, and a perception that many of the concerns identified during the first evaluation had received attention a year later, highlighting the positive impact of regular evaluation mechanisms. Secondly, the two main spheres of concern, that had not been adequately addressed yet related to issues of client drop-out and relapse, as well as the absence of adequate on-going mechanisms for documenting and measuring the effectiveness of the programme.

\section{Lessons for public treatment programmes}

Given the extent of substance abuse in South Africa, and particularly the tik and heroin problems in the Western Cape, it is clear that effective evidence-based interventions are urgently needed in the public sector (Lund, Stein, Corrigall, Bradshaw, Schneider \& Flisher, 2008; Myers, Harker, Fakier, Kader \& Mazok, 2008b). The evaluations of the programme presented in this paper provide valuable indications of those factors which enable effective programme functioning, as well as the challenges needing to be addressed in enhancing service delivery in this sector.

Firstly, in view of the complex and multifaceted nature of substance abuse, a model of intervention is needed which is able to respond to the many challenges faced by substance abusers in their attempts to achieve and maintain abstention. Hence the value of a collaboration between, in this instance, the Departments of Social Development and of Health, which allows for attention to both the social and health and mental health problems that many patients face through a one-stop multi-disciplinary programme (Corrigall et al., 2007; Department of Social Development, 2007). However, as emerged from this study, these two government sectors alone are not necessarily well placed to deal with the many other issues that confront the recovering addict (for example, lack of skills and employment 
opportunities; entrenched gangsterism in some communities; lack of recreational opportunities), especially when participating in an out-patient programme. Thus the value of collaborating with other government departments and civil society organisations, in order to facilitate the career development and job skills training needs of those making use of the programme (Corrigall et al., 2007; UNODC, 2008b).

Another factor which emerged as key to the effectiveness of treatment programmes relates to the nature of the selected intervention model. While literature points to a wide range of substance abuse treatment models, with different strengths and weaknesses, what was considered important for this programme was the adoption of an evidence-based programme, suitable for out-patient implementation (Lund et al., 2008; Myers et al., 2008b). Hence the choice of a cognitive-behavioural model with a history of effectiveness in addiction treatment (Myers et al., 2008b; Rawson, Marinelli-Casey, Anglin, Dickow, Frazier, Gallagher, Galloway, Herrell, Huber, McCann, Obert, Pennell, Reiber, Vandersloot, Zweben \& the Methamphetamine Treatment Project Corporate Authors, 1999; Rawson \& McCann, 2002; Shoptaw, Rawson, McCann \& Orbert, 1994). The evaluations demonstrated that it was the comprehensive, structured, incentivised group-based nature of this model which was most highly regarded by staff and clients alike, and which seemed to be especially successful with tik abusers.

The evaluation also pointed to features of the model (referred to below) which could be strengthened to maximise impact, many of which would be likely to be relevant for any such programme implementation. Thus the manuals and materials used by staff and clients need to be adapted to local conditions and available in the home languages of clients. In addition to the group sessions of the core programme, the role of aftercare services and family involvement were identified as central to rehabilitation, needing careful attention as to how best to integrate, extend and formalise their inclusion in the programme. Moreover, the need for more individual counselling, especially in the first few weeks of treatment, was identified as a key factor in reducing drop-outs in this high-risk period of rehabilitation. Also, there is a need to expand the range of client activities offered, as a common drawback of out-patient services is that substance abusers continue to be confronted by the many triggers of their daily home/community lives. This is where local structures could play an important part in offering additional educational and recreational activities (UNODC, 2008a, 2008b).

Another significant feature of the treatment model is the nature of the staff complement. While it was found in this study that the staff were generally highly regarded by clients, given the multidisciplinary format of the treatment model, staffing presents particular challenges in that those from different disciplinary backgrounds needed to be thoroughly orientated to the various components of the approach. Also, the need for on-going staff training, support and supervision was seen as crucial. Moreover, the organisational climate requires continuous attention, especially regarding different disciplinary roles and the need for transparent processes and consultation (Greener, Joe, Simpson, Rowan-Szal \& Lehman, 2007; Moos \& Moos, 1998). 
One of the main challenges of this programme, and others more generally, is that of retention of clients, and the reduction in the numbers of drop-outs and relapses (UNODC, 2008a). Addiction is widely understood as a chronic relapsing disorder, thereby making the prevention of relapse one of the critical elements of effective treatment. Studies have shown that $54 \%$ of all alcohol and drug abuse patients can be expected to relapse, and that $61 \%$ of those will have multiple episodes of relapse (Simpson, Joe, Lehman \& Sells, 1986). The evaluations reported on in this study identified some possible strategies for tackling this challenge. More data on the dynamics of retention and dropping out need to be generated; clear ways of monitoring and tracking individual progress within the programme and during after-care need to be delineated and implemented; and strategies and practices with respect to follow up of drop-outs need to be reviewed, including the possibility of involving local community-based organisations to assist in tracking and following up clients who drop out.

Finally, a major challenge to the successful implementation of this substance abuse treatment programme was the lack of a streamlined, accessible and centralised electronic system of client record keeping/data collection to allow for on-going and effective monitoring and evaluation of the programme. This appears to be a generalised shortcoming of South African substance rehabilitation programmes (Harker Burnham, Myers, Falkier, Parry \& Carelse, 2011; Myers, Harker Burnham \& Fakier, 2009). Suggestions emerging from this study include that the process should start in the planning stages of the programme, and should be preceded by the development of clear indicators of success of the programme and measurable outputs, based on the key goals of the programme, which in turn would determine the structure and categories of data that need to be captured on client progress. Such documentation of client responses to the programme would not only allow for better overall assessment of the effectiveness of the programme, but would also contribute to more focused attention to the particular needs of individual clients and thereby potentially also address retention issues, as mentioned above. Finally, it would also be important to have information on the effectiveness of other out-patient programmes, both locally and internationally, against which to assess the performance of the programme (e.g. Myers et al., 2008b).

In conclusion, these evaluations highlight the value of a community-based out-patient substance abuse treatment programme, which is based on a recognised model, but which has been adapted to the local context and addresses the complexity of the issues involved. They also confirm the importance of implementing appropriate mechanisms for continuous assessment of the effectiveness of such interventions.

\section{ACKNOWLEDGEMENTS}

The authors wish to acknowledge and thank the South African National Council on Alcohol and Drug Abuse (SANCA), Western Cape, and in particular the Sinethemba Programme, and its funders the provincial Departments of Social Development and Health, Western Cape. 


\section{REFERENCES}

BRAUN, V. \& CLARKE, V. 2006. Using thematic analysis in psychology. Qualitative Research in Psychology, 3(2):77-101.

CENTER FOR SUBSTANCE ABUSE TREATMENT. 2005. Substance abuse treatment for persons with co-occurring disorders. Treatment Improvement Protocol (TIP) Series 42. DHHS Publication No. (SMA) 05-3992. Rockville, MD: Substance Abuse and Mental Health Services Administration.

CORRIGALL, J., WARD, C., STINSON, K., STRUTHERS, P., FRANTZ, J., LUND, C.; FLISHER, A.J. \& JOSKA, J. 2007. Decreasing the burden of mental illness. Western Cape Burden of Disease Reduction Project (vol 4/7).

DADA, S., PLÜDDEMANN, A., PARRY, C., VAWDA, M. \& FOURIE, D. 2012. South African Community Epidemiology. Update (June). [Online] Available: http:// www.sahealthinfo.org/admodule/sacendu/UpdateJune2012.pdf [Accessed: 18/10/2012].

DEPARTMENT OF SOCIAL DEVELOPMENT. 2007. National drug master plan 20062011. Pretoria: Department of Social Development.

GREENER, J.M., JOE, G.W., SIMPSON, D.D., ROWAN-SZAL, G.A. \& LEHMAN, W.A.K. 2007. Influence of organizational functioning on client engagement in treatment. Journal of Substance Abuse Treatment, 33(2):139-147.

HARKER, N., KADER, R., MYERS, B., FAKIER, N., PARRY, C., FLISHER, A.J., PELTZER, K., RAMLAGAN, S. \& DAVIDS, A. 2008. Substance abuse trends in the Western Cape: a review of studies conducted since 2000. (Commissioned by the Department of Social Development, Cape Town).

HARKER BURNHAM, N., MYERS, B., FALKIER, N., PARRY, C. \& CARELSE, J. 2011. Establishing a computerized substance abuse surveillance system for district social workers in the Western Cape Province, South Africa: Methods, successes and challenges. Drugs: Education, Prevention and Policy, 18(1):40-46.

KANSKY, R. 2008. A process evaluation of the Athlone/Gugulethu branch of SANCA, with particular reference to the Sinethemba Programme. Stellenbosch: University of Stellenbosch. (Unpublished report)

LUND, C., STEIN, D.J., CORRIGALLI, J., BRADSHAW, D., SCHNEIDER, M. \& FLISHER, A.J. 2008. Mental health is integral to public health: a call to scale up evidence-based services and develop mental health research. Editorial. South African Medical Journal, 98:444-446.

MOOS, R.H. \& MOOS, B. 1998. The staff workplace and the quality and outcome of substance abuse treatment. Journal of Studies on Alcohol, 59:43-51.

MYERS, B. 2006. Methamphetamine abuse, psychosis and your patient. South African Family Practice, 48(2):56-57. 
MYERS, B., LOUW, J. \& FAKIER, N. 2008a. Alcohol and drug abuse: removing structural barriers to treatment for historically disadvantaged communities in Cape Town. International Journal of Social Welfare, 17:156-165.

MYERS, B., HARKER, N., FAKIER, N., KADER, R. \& MAZOK, C. 2008b. A review of evidence-based interventions for the prevention and treatment of substance use disorders. Technical Report. Medical Research Council, South Africa.

MYERS, B., HARKER BURNHAM, N. \& FAKIER, N. 2009. Monitoring and evaluation of substance abuse services in South Africa: implications for policy and practice. International Journal of Mental Health and Addiction, 8(4):557-565.

MYERS, B. \& FAKIER, N. 2009. Provision of mental health services in South African substance abuse treatment facilities. International Journal of Mental Health and Addiction, 7(3):441-449.

MYERS, B., FAKIER, N. \& LOUW, J. 2009. Stigma, treatment beliefs, and substance abuse treatment use in historically disadvantaged communities. African Journal of Psychiatry, 12:218-222.

PARRY, C.D.H., PLÜDDEMANN, A., LOUW, A. \& LEGGETT, T. 2004. The 3-metros study of drugs and crime in South Africa: Findings and policy implications. American Journal of Drug and Alcohol Abuse, 30(1):167-185.

PARRY, C.D.H. 2005. Substance abuse intervention in South Africa. World Psychiatry, 4(1):34-35.

PARRY, C.D.H., BLANK, M.B. \& PITHEY, A.L. 2007. Responding to the threat of HIV among persons with mental illness and substance abuse. Current Opinion in Psychiatry, 20:235-241.

PLÜDDEMANN, A., PARRY, C.D.H., DONSON, H. \& SUKHAI, A. 2004. Alcohol use and trauma in Cape Town, Durban and Port Elizabeth, South Africa: 1999-2001. Injury Control and Safety Promotion, 11(4):265-267.

PLÜDDEMANN, A., MYERS, B. \& PARRY, C.D.H. 2008. Surge in treatment admissions related to methamphetamine use in Cape Town, South Africa: implications for public health. Drug and Alcohol Review, 27(2):185-189.

PLÜDDEMANN, A., PARRY, C., DADA, S., BHANA, A., BACHOO, S. \& FOURIE, D. 2010. South African Community Epidemiology Network on Drug Use (SACENDU) Update (December, 2010). [Online] Available: www.sahealthinfo.org/admodule/ sacendu.htm [Accessed: 18/10/2012].

RAWSON, R.A., MARINELLI-CASEY, P., ANGLIN, D., DICKOW, A., FRAZIER, Y., GALLAGHER, C., GALLOWAY, G.P., HERRELL, J., HUBER, A., McCANN, M.J., OBERT, J., PENNELL, S., REIBER, C., VANDERSLOOT, D., ZWEBEN, J. \& the Methamphetamine Treatment Project Corporate Authors. 1999. A multi-site comparison of psychosocial approaches for the treatment of methamphetamine dependence. Addiction, 99:708-717. 
RAWSON, R. \& McCANN, M.J. 2002. The Matrix model of intensive outpatient treatment: A guideline developed for the Behavioral Health Recovery Management project. Journal of Substance Abuse Treatment, 23:107-113.

SHOPTAW, S., RAWSON, R.A., McCANN, M.J. \& OBERT, J.L. 1994. The Matrix model of stimulant abuse treatment: evidence of efficacy. Journal of Addictive Diseases, 13:129-141.

SIMPSON, D.D., JOE, G.W., LEHMAN, W.E.K. \& SELLS, S.B. 1986. Addiction careers: etiology, treatment, and 12-year follow-up outcomes. Journal of Drug Issues, 16(1):107121.

SAMHSA (Substance Abuse and Mental Health Services Administration) 2005. Results from the 2004 national survey on drug use and health: National findings. NSDUH Series H-28. DHHS Publication No. (SMA) 05-4062. Rockville, MD: Office of Applied Studies.

STARAS, S., TOBLER, A., MALONADO-MOLINA, M. \& COOK, R. 2011. Riskier sexual partners contribute to the increased rate of sexually transmitted diseases among youth with substance use disorders. Sexually Transmitted Diseases, 38(5):413-418.

UNODC (United Nations Office on Drugs and Crime). 2008a. Drug-dependency treatment: Community based treatment. Treatnet: International Network of Drug Dependence Treatment and Rehabilitation Resource Centres: Good practice document. [Online] Available: http://www.unodc.org/treatnet [Accessed: 18/10/2012].

UNODC (United Nations Office on Drugs and Crime). 2008b. Drug-dependency treatment: Sustained recovery management. Treatnet: International Network of Drug Dependence Treatment and Rehabilitation Resource Centres: Good practice document. [Online] Available: http://www.unodc.org/treatnet [Accessed 18/10/2012].

VAN HEERDEN, M.S., GRIMSRUD, A., SEEDAT, S., MYER, L., WILLIAMS, D. \& STEIN, D. 2009. Patterns of extra-medical drug use in South Africa: results from the South African Stress and Health Study. South African Medical Journal, 99(5):358-366.

WECHSBERG, W.M., JONES, H.E., ZULE, W.A., MYERS, B.J., BROWNE, F.A., KAUFMAN, M.R., LUSENO, W., FLISHER, A.J. \& PARRY, C.D. 2010. Methamphetamine ("tik") use and its association with condom use among out-of-school females in Cape Town, South Africa. American Journal of Drug \& Alcohol Abuse, 36(4):208-13.

WEICH, L. \& PIENAAR, W. 2009. Occurrence of comorbid substance use disorders among acute psychiatric inpatients at Stikland Hospital in the Western Cape, South Africa. African Journal of Psychiatry, 12(3):213-217.

Dr Anna Strebel, Prof Tamara Shefer, Women's and Gender Studies, University of the Western Cape; Ms Maria Stacey SWEAT (Sex Worker Education and Advocacy Taskforce); Prof Nokuthula Shabalala, Psychology Department, University of Cape Town, Cape Town, South Africa. 